\title{
Novel Manufacturing Process of Two New Soykasu Products from Waste Residue of Soymilk and Tofu Production Units
}

\author{
Mansi Y Chaudhari1, Neha Y Chaudhari' \\ ${ }^{1}$ UG student, Chemical Engineering, GSFC University, Vadodara, India \\ ${ }^{2}$ UG student, Chemical Engineering, Parul Institute of Engineering and Technology, Vadodara, India
}

\begin{abstract}
The aim of this article is to reduce food loss in the form of soymilk residue generated during production and processing of soymilk and tofu from soybeans by Preparation and method development of utilizing this soymilk residue into nutritious, more healthy, low cost and full of protein flour compared to other grain flour and probiotic beverage. SOYKASU will definitely play an important role as it contributes in health and agriculture as well as help us in waste management with profitable output. For production of SOYKASU products, the soy milk residue slurry is first washed and cleaned to remove unwanted dust then is autoclaved at $121^{\circ} \mathrm{C}$ for about 2-3 minutes. This mixture flows over strainers that capture the fibrous solids but allow the water to pass through then the solid cake is divided into two sections for production of flour and probiotic beverage then is combined with acid and enzymes that breaks the long chain molecules into simpler molecules. Then both the products after various microbial actions are deodorized to remove the unwanted odour. The flour formed is in lumped form hence a series of lump crusher and grinders is introduced to form fine particles and packed as final product. The probiotic beverage is directly packed after deodorizing.

Keywords: Soykasu, soymilk, soymilk residue, food waste, soybean, Probiotic beverage, nutrients, health
\end{abstract}

\section{INTRODUCTION}

According to the survey conducted by Food and Agriculture Organisation (FAO) Over 7000 Indians die every day due to hunger, 2 in every 10 people go to sleep hungry at night and 3000 children die every day because of poor diet related diseases, Anaemia is severe in both women and pre-school children. This is not because our farmers do not produce enough food for all but because almost $40 \%$ of what we produce is wasted. That's why India must strive to meet target to reduce food losses along production and supply chains including post-harvest losses [1].

Food loss refers to the amount of healthy food created for the consumption of individuals gets wasted. Loss is taken into account with respect to non-food consumption (animal feed, bio-power) additionally. Food loss usually takes place at production, post-harvest, processing and distribution stages within the food offer/supply chain [1].

Global food waste contributes considerably to environmental problems, as it uses extensive energy and resources and additionally associated with greenhouse gas emissions [2]. The world already wastes one third of its food and the COVID-19 Pandemic is probably going to push food wastage further due to improper harvesting of food crops at time due to lock down, use of rice buffer stocks in making/creating sanitizers, unfavourable conditions for food supply chain and plenty more such reasons.

Soykasu is a small initiative to stop this food wastage and convert it into useful, healthy and low cost, easily accessible product which will be used to feed such poor people at a very nominal rate with appropriate amount of nutrition by processing the soybean based food waste generated in soymilk and tofu production unit.

Currently, India ranks fifth in respect to production of soybean in the world [3]. The crop helps earn valuable foreign interchange (Rs. 62000 millions in 2012-13) by way of soya product exports [4]. Soybean has mostly been accountable in rising farmer's economic standing in several pockets of the country. It usually fetches higher income to the farmers of the country through export market.

Soy milk/Tofu residue is the ground up fibrous part of soy bean. It contains insoluble parts of soybean which is remained after crushed soybeans are filtered while producing Soy milk and tofu. Each kilogram of Soy Bean which is used to produce soymilk or tofu, about $1.1-1.2 \mathrm{~kg}$ of residue is formed [5]. Its main components are broken cotyledon cells and the coating of Soy Beans. Currently, Residue is treated as waste and is either used as feed, fertiliser and mostly land filled or rarely used for consumption as fresh food in some countries like China, Japan and Korea (no traces of consumption in India).

\section{PROPOSED WORK}

The manufacturing of SOYKASU flour and Probiotic beverage involves the following operations/ processes:

A. Inspection and Cleaning

B. Washed out residue Straining

C. Autoclave boiling

D. Flour manufacturing by Fermentation

E. Probiotic beverage manufacturing by Fermentation

F. Deodorizing of flour and probiotic beverage

G. Drying of product flour

H. Lump fine Grinding

I. Packaging of final products

2.1 Inspection and Cleaning

The soy milk residue from soymilk and tofu production plant 
passes through mechanical cleaners designed for cleaning which is designed accordingly to remove unwanted items, such as pieces of wood, sand and stone. Cleaners annoy residues on top of a series of thinly sliced metal stones where foreign goods are rejected. A blast of air blows away dust particles and electromagnets remove bits of metal coming out of storage bins, the soymilk residue is given water wash cleaning before going into "autoclave boiling" tanks.

\subsection{Washed Out Residue Straining}

After washing and cleaning soy milk residue is sent for dewatering to separate residue from water using a fine mesh size strainer and the separated residue is sent to autoclave boiler for further processing.

\subsection{Autoclave Boiling}

Auto clave boiler is equipment designed as a jacketed vessel to provide high pressure steam. In autoclave boiler, the cleaned residue is heated at the temperature of about $121^{\circ} \mathrm{C}$ for about $3-5$ minutes and a high pressure compressed air is provided. The extra pressure in autoclave means that water boils at temperature higher than its normal boiling point-roughly $20^{\circ} \mathrm{C}$ hotter- so it holds and carries more heat and kills unwanted and harmful bacteria more effectively. As a lengthy blast of high pressure is much more effective at penetrating and sterilizing things than a quick wipe in ordinary hot water. After removing excess water from the residue, the residue is divided into two equal parts and fermented separately using different microorganisms.

\subsection{Flour Manufacturing By Fermentation}

Fermentation is a biotechnological process that can be used to stimulate the valorisation of the sustainability of soymilk residue as well as enhance its nutritional and functional properties

The half portion of autoclaved soy milk residue is fermented using two micro-organisms namely:

\section{- Rhizopus oligosporos}

- Yarrowia lipolytica

The soymilk residue is fermented for 2-3 days which reduce the content of raw fibre, increase the content of soluble fibre, proteins, amino acids and isoflavones, and decomposition of phytic acid (a deposit of phosphorus in seeds that are indigestible and chelate other nutrients, while in herbivorous animals it is lysed by bacterial flora), which leads to improvements in the nutritional value and processing properties of soy milk residue.

\subsection{Probiotic Beverage Manufacturing by Fermentation}

Probiotics are living germs, which when given are controlled in adequate amounts confer a health benefit to the host.

The half portion of autoclaved soy milk residue is fermented using two micro-organisms namely:

\section{- Lactobacillus paracasei [LAFTI L26]}

The soymilk residue is fermented for 4-5 days with water and micro-organism which completely decomposes the soymilk residue and convert them into fine colloidal particles which gets uniformly mixed in water to form a perfect probiotic beverage. The conversion of the insoluble dietary fibres of residue into soluble fibres is observed. This fermentation shown to possess increased antioxidant activity. Soymilk residue provides a surface for bacteria-cell adhesion, thus facilitating substrate absorption and cell growth.

\subsection{Deodorizing of Flour and Probiotic Beverage}

SOYKASU has a green, grassy off odour as it contains a large amount of aldehydes. Hence to remove this odour bioconversion of this aldehyde present in SOYKASU is done using one yeast namely:

\section{- Lindnera saturnus}

This yeast leads to formation of aldehydes in SOYKASU to bioconversion into natural fruity, pleasant-smelling esters. Lindnera saturnus increases the amount of esters by about 70 times to $165-277 \mu \mathrm{g} / \mathrm{g}$ of SOYKASU. Probiotic beverage is ready for packaging and supplying and the SOYKASU flour is sent to the drying section for further processing.

\subsection{Drying of Flour}

The SOYKASU flour passes through a chute to be heated in rotary co-current dryer for reducing its moisture content. Hot air with a temperature of about $180-200^{\circ} \mathrm{C}$ is provided by burning natural gas in the furnace. Lumps leaving dryer are so dried as to have a moisture content of less than one percent. The furnace is provided with a burner and a burner fan for supplying air required for combustion.

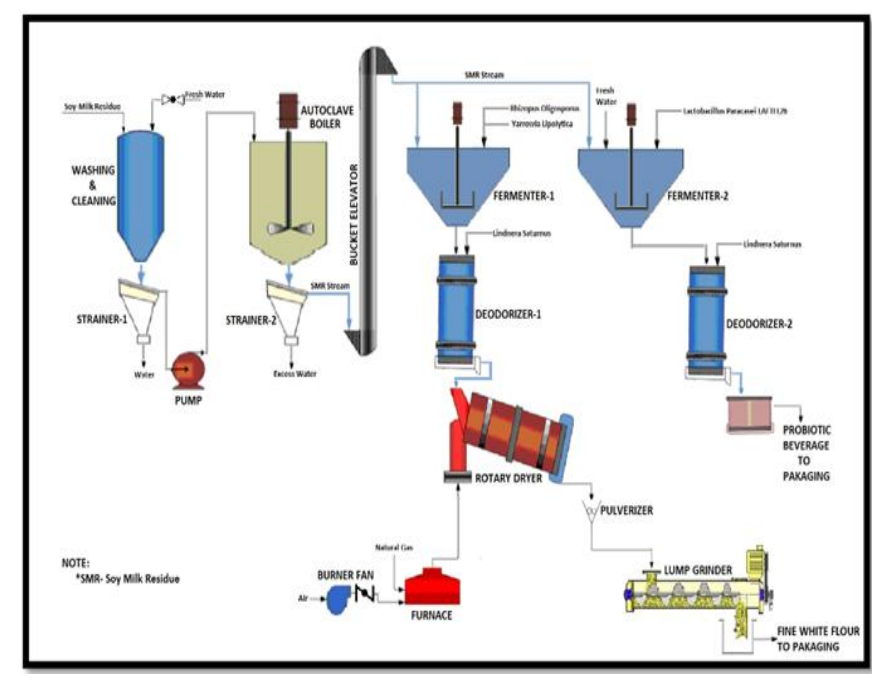

Fig. 1 Process Flow Sheet for Production of Soymilk/Tofu Residue waste Flour and Probiotic Beverage

\subsection{Lump fine Grinder}

Dried product flour is in the form of lump which is needed to be ground to form fine and uniform edible flour. Hence the dried SOYKASU flour is passed through series of crushers and grinders. At first it passes through gyratory crusher then finally through flour grinder machine to form the flour of dried SOYKASU. Two magnet types of screens are provided for screening. Over sizes from screen are fed to recycle conveyor via oversize mill where oversize is crushed. The fines/undersize from screen is fed to product cooler which is rotary drum type cooler where product is cooled by ambient counter-current air.

\subsection{Packaging of final products}

The final products, SOYKASU FLOUR from product cooler and SOYKASU PROBIOTIC BEVERAGE from deodorizer after quality assurance are sent to last section for bagging and packaging section. 


\section{RESULTS}

\subsection{Nutrients in Product}

Proposed process offers tremendous products that possess health benefits when incorporated into regular diet [6]. It's an inexpensive, high quality, vitamin and mineral rich, protein with lots of soluble fibre, plant based Omega-3 fatty acids and a wealth of disease fighting phytonutrients which provides a high amount of healthy food as well as potential prebiotic elect. It is therefore potentially useful as a functional ingredient with health-promoting properties.

The various nutrients present in SOYKASU are: Alpha lipoic acid, Ascorbic acids, B Vitamins, Isoflavones [7], Beta-Carotene, Glutathione, Lutein/Zeaxanthin, Phytosterols, Phytic acid, Saponins, Vitamin and many more nutrients.

\subsection{Health Benefits}

Amazing health benefits of SOYKASU flour and Probiotic Beverage are: Better immune system, Helps prevent diabetes, Helps prevent premature ageing, Improves metabolism, Helps proper blood circulation, Boosts digestive health, Good for nails, Combats hearing loss, Good for brain, Good for pregnant mothers, Helps fight depression, Relieves from sleep disorder, Good for cognitive ability.

Besides this the five major health benefits of the products are: Keep bones stronger, Good for Heart, Lowers Cancer Risk, Reduces Menopausal Symptoms [7] and Probiotic Beverage helps to Balance Friendly Bacteria in Digestive System and reduces obesity [8].

\section{CONCLUSION}

The total focus of our proposed article is to reduce the food wastage and to promote a business strategy to make a perspective view of society to take this food loss as an opportunity to change this waste into a source of contribution into healthy environment and society along with generating capital through wastage and thus contributing a little in country's economy also.

\section{REFERENCES}

[1] FAO: Global Food Losses and Food Waste. 2011 [Retrieved 01.05.2014]. Available online: http://www.fao.org/docrep/014/mb060e/mb060e00.pdf (accessed on 20 December 2019).

[2] FAO: Food Wastage Footprint-Impacts on Natural Resources. 2013 [Retrieved 01.05.2014]. Available online: http://www.fao.org/docrep/018/i3347e/i3347e.pdf (accessed on 20 December 2019).

[3] Karuga, J. 10 Countries with Largest Soybean Production. World Atlas. 2018. Available online: worldatlas.com/articles/world-leaders-in-soya-soybeanproduction-by-country.html (accessed on 18 March 2020).

[4] FICCI: Industry's voice for policy change report Available online: http://ficci.in/spdocument/20539/soybean-report.pdf

[5] Khare, S.K.; Jha, K.; Gandhi, A.P. Citric acid production from okara (soy residue) by solid-state fermentation.Biores. Technol. 1995, 54, 323-325.

[6] Messina, M. Soy and health update: Evaluation of the clinical and epidemiologic literature. Nutrients 2016, 8,754.

[7] Chen, L.-R.; Ko, N.-Y.; Chen, K.-H. Isoflavone Supplements for Menopausal Women: A Systematic Review. Nutrients 2019, 11, 2649

[8] Matsumoto, K.; Watanabe, Y.; Yokoyama, S. Okara, soybean residue, prevents obesity in a diet-induced murine obesity model. Biosci. Biotech. Bioch. 2007, 71, 720-727. 